\title{
HERMENÊUTICA E DEMOCRACIA: A VERDADE COMO CONSENSO
}

\author{
Luiz Alberto G.S. Rocha \\ luizalbertorocba@unama.br \\ Doutor pela FADUSP. Professor Titular da \\ Universidade da Amazônia - UNAMA. \\ André Martins Brandão \\ andrembrandão@gmail.com \\ Mestre em Direito pela UNAMA e \\ Advogado \\ Recebido em 24/02/2012 \\ Aprovado em 19/10/2012
}

\begin{abstract}
Resumo
O trabalho busca traçar algumas linhas que colaborem para uma interpretação mais democrática do direito em nossa sociedade, se valendo de investigações hermenêuticas a respeito da interpretação e aplicação do direito. Para tanto na primeira parte demonstramos o direito como um sistema aberto de significado, do qual diversas significações podem ser extraídas dependendo daquele que a está realizando. $\mathrm{Na}$ segunda parte, por sua vez, trabalhamos

com duas teorias: uma de Ronald Dworkin
\end{abstract}

sobre a verdade jurídica; e outra de Aulis Aarnio sobre a legitimidade das interpretações, em ordem de encontrar mecanismos para uma interpretação mais democrática do direito.

\section{Palavras-chave}

Hermenêutica, Democracia, Interpretação, Consenso, Verdade. 


\title{
HERMENEUTICS AND DEMOCRACY: THE TRUTH AS CONSENSUS
}

\author{
Luiz Alberto G.S. Rocha \\ André Martins Brandão
}

Abstract

This essay seeks to underlaine some lines that help for a more democratic interpretation of the law in our society, taking as basis the hermeneutics investigations concerning interpretation and application of the law. For that, in the first part, we will demonstrate the law as an open-meaning system, from which innumerous significations can be extracted from depending on whom is working with. In the second part, for this way, we will work with two

theories: one's ofRonald Dworkin on legal truth; and the other of Aulis Aarnio's on the interpretation of legitimacy, in order to find mechanisms for a more democratic interpretation of law.

Keywords

Hermeneutics, Democracy, Interpretation, Consensus, Truth. 
Sumário

1.Um sistema jurídico hermeneuticamente aberto.

2. Democracia e legitimidade: a busca cooperativa.

3. Considerações Finais. 4. Referências. 


\section{Um sistema jurídico hermeneuticamente aberto.}

A hermenêutica é assim chamada devido a uma importante divindade do panteão grego. Essa divindade tem o nome de Hermes, que posteriormente foi rebatizado por Mercúrio na Roma antiga. Filho de Zeus e Maia, Hermes significava a supremacia na decifração de palavras divinas, era o mensageiro dos deuses, aquele capaz de transmitir o sagrado tornando-o compreensível a todos. Por meio desse mito podemos já vislumbrar o ato hermenêutico como uma diç̧ão translativa, uma forma de decifração da linguagem revelando o que se encontra fechado, escondido no seu interior. A respeito desse mito Richard Palmer escreve com mestria:

Os gregos atribuíam a Hermes a descoberta da linguagem e da escrita - ferramentas que a compreensão humana utiliza para chegar ao significado das coisas e para transmitir aos outros (...). Assim, levada até sua raiz grega mais antiga, a origem das actuais palavras hermenêutica e hermenêutico sugere o processo de tornar compreensível, especialmente enquanto tal processo envolve a linguagem, visto ser a linguagem o meio por excelência deste processo. ${ }^{1}$

Nesse contexto devemos entender o que é hermenêutica jurídica e o que ela proporciona para a teoria do direito. A teoria do direito deve ser entendida, como qualquer outra teoria geral, como uma tese sobre a coisa, nesse caso uma teoria sobre o objeto direito, presente em quase todas as sociedades ocidentais pósmodernas. Se a teoria é sobre a coisa, logo a hermenêutica é a forma de conhecer a coisa. Ela nos mostra caminhos a serem seguidos para interpretar e conhecer um objeto, e, no nosso caso, mostra caminhos para conhecer o direito.

A hermenêutica assim é a ciência da interpretação, o lugar comum para os intérpretes, o caminho a ser seguido para o conhecimento de um objeto. Faremos uso desta ciência para demonstrar que o sistema jurídico é hermeneuticamente aberto, ou seja, livre de significado e objetivo.

A primeira lição hermenêutica que iremos trabalhar diz respeito à interpretação e à necessidade do intérprete. Para toda a interpretação deve existir um intérprete. Não existe tal coisa como uma interpretação legítima que exista por si só, todo o texto ou fato necessita de um intérprete para ser interpretada, revelando assim um de seus possíveis significados. O conhecimento fenomênico é sempre uma correlação entre sujeito e objeto, logo depende de um estudante e um objeto de estudo, ou seja, de um intérprete e de uma situação a ser interpretada.

Benedito Nunes ${ }^{2}$, em texto sobre a obra de Martin Heidegger, revela que para o alemão "existir é interpretar-se. E interpretar-se é questionar-se". Nesse

PALMER, Richard E. Hermenêutica. Lisboa: Edições 70, 1969, p. 24.

NUNES, Benedito. Heidegger \& Ser e Tempo. Rio de Janeiro: Jorge Zahar, 2002, p.13. 
diapasão, o homem caminha no mundo interpretando-o, sendo impossível separar a existência humana da interpretação do sistema em que vivemos.

Ainda paira por sobre nossas cabeças no mundo jurídico "a afirmação de que somente seria necessário interpretarmos normas quando o sentido delas não fosse claro". ${ }^{3}$ Nesse entendimento, aliás, existiriam normas que não precisariam ser interpretadas por um sentido em si, aquele desejado pelo legislador, não sendo necessária sua interpretação. Ao longo desse estudo combateremos esse entendimento, demonstrando que toda a norma necessita de interpretação, e que essa caminha sempre junto a aplicação do direito, pois, como vimos, a existência humana é inseparável da interpretação.

O intérprete, por sua vez, interpreta a situação a partir de seus próprios conhecimentos e experiências anteriores, interpreta a partir do que já conhece como mundo. O conhecimento adquirido realiza o conhecimento do objeto a sua própria luz, dando-lhe feição nova e única. Deste modo, toda a compreensão depende de uma pré-compreensão, todo o conceito depende de um preconceito, uma vez que interpretamos sempre o novo tendo por base o passado. Esse fato é inerente ao ser humano, uma atividade até subconsciente. Sempre procuramos um significado para o mundo baseado em nossas prévias convicções.

Cabe ressaltar que o preconceito necessário para o conceito não é sempre negativo. ${ }^{4}$ A palavra preconceito é usada comumente em nossa sociedade com viés pejorativo. Quem tem preconceito na língua comum tem alguma prévia concepção negativa sobre algo. Aqui a palavra preconceito não tem esse mesmo significado. A partir dos estudos de Heidegger, seguido por Gadamer ${ }^{5}$, o preconceito pode ser tanto negativo quanto positivo, não constituindo assim um falso juízo, e sim um juízo prévio, que pode vir a ser ou não confirmado.

Se se quer fazer justiça ao modo de ser finito e histórico do homem, é necessário levar a cabo uma drástica reabilitação do conceito de preconceito e reconhecer que existem preconceito legítimos. ${ }^{6}$

3 GRAU, Eros. Ensaio e Discurso sobre a interpretação/aplicação do direito, $4^{a}$ ed. São Paulo: Malheiros, 2006. p. 25.

$4 \quad \mathrm{Na}$ verdade qualquer teoria do conhecimento não pode aferrar-se ao completo ineditismo do conhecimento porque a racionalização das idéias formam-se a partir de bases metodológicas previamente determinadas e ensinadas pela geração antecedente. Mesmo a contestação dos preconceitos (quebra de paradigma) requerem a substituição por novos que lhe tomem o lugar e a função.

5 GADAMER, Hans-Georg. Verdade e método: traços de uma hermenêutica filosófica, $3^{\mathrm{a}}$ ed. Petrópolis: Vozes, 1999, p. 407.

6 GADAMER, Hans-Georg. Verdade e método: traços de uma hermenêutica filosófica, $3^{\mathrm{a}}$ ed. Petrópolis: Vozes, 1999., p. 416. 
Então nunca vemos as coisas por si só, vemos sempre como nossa percepção permite capturá-las ainda que não tenhamos completo controle (consciência) deste processo, pois todo o conceito nasce de um preconceito. Cada um tem a sua própria visão de realidade baseada em sua própria experiência fenomênica, interpretando cada situação como sua perspectiva individual permite interpretar. Em seu estudo sobre a obra de Heidegger, Benedito Nunes clarifica no que consiste a interpretação para esse autor, mostrando que ela depende de conceitos prévios (preconceitos) como referenciais para se chegar a um sentido possível da linguagem.

A interpretação nada mais é do que o desenvolvimento do compreender apropriando-se das possibilidades em que o poder-ser se projeta. Mas essa apropriação não é jamais algo sem pressuposto: parte de um referencial que se tem (Vorhabe), explicita-se em conceitos prévios (Vorgriffe) numa certa perspectiva (Vorsicht). O sentido dessa apropriação já é discursivo, mas não proposicional. Comensurando a abertura, o discurso comensura a linguagem ao ouvir (Horen) e silenciar (Schweigen), que são suas possibilidades. ${ }^{7}$

Podemos nesse momento argüir então que o objeto de conhecimento e o conhecimento do objeto são coisas diferentes e que não podem ser confundidos. Isto porque o objeto de conhecimento é aquele que o pesquisador se propõe a investigar, enquanto o conhecimento do objeto é conclusão a qual se chega, sempre contaminada pelo subjetivismo do sujeito, pela parcialidade daquele que investiga, pois o objeto foi conhecido a partir de preconceitos individuais.

Nesse contexto, a partir da invasão da linguagem na filosofia conhecida como giro linguístico, essa passou a ter uma forte significação para o homem. Ao deixar de ser enxergada como barreira entre o sujeito e o objeto, e passar a ser a forma última de experiência com a realidade, a linguagem ganhou status de essencialidade para a sociedade, ela "se converte em ponto de partida e centro de reflexão" ${ }^{8}$ de todo o conhecimento humano, baseada em algumas premissas elencadas por Lênio Streck:

(a) O conhecimento ocorre na linguagem. (...) (b) É na linguagem que há a surgência do mundo. É na linguagem que o mundo se desvela. (...) (c) É na linguagem que o ser surge-aparece-ocorre. Como sujeito que fala, como sujeito de enunciação, e como sujeito que entende a linguagem dos outros. (...) (d) É na linguagem que ocorre a ação. Não só a linguagem tem vocação representativa, declarativa ou constatativa. Também existe a vocação realizativa da linguagem, que conecta a linguagem com a prática, assim como a prática e os interesses com a linguagem. (e) É na linguagem que se dá o sentido. O sentido do que há, em primeiro lugar, porque a linguagem tem necessariamente um componente significativo para uma comunidade de usuários que

NUNES, Benedito. Heidegger \& Ser e Tempo. Rio de Janeiro: Jorge Zahar, 2002,., p.17.

8 STRECK, Lênio Luiz. Hermenêutica Jurídica e(m) crise: uma exploração hermenêutica da construção do direito. Porto Alegre: Livraria do Advogado, 1999, p. 151. 
sem ela não funciona; segundo lugar, a linguagem pode criar novos mundos na medida que abre outros caminhos ao sentido. Nomear, adjetivar, em certo sentido, é criar. ${ }^{9}$

A partir dessa concepção podemos corroborar a máxima heideggeriana de que a linguagem é a morada do ser, pois é por meio dela que interpretamos e compreendemos o mundo, as outras pessoas e os seres a nossa volta. Até mesmo nossos pensamentos funcionam de forma lingüística. A linguagem é o veículo último de comunicação e compreensão do mundo, logo o habitat natural do ser. Sem a linguagem não existe mundo.

Por isso que Gadamer vai dizer que a hermenêutica como teoria filosófica diz respeito a totalidade do nosso acesso ao mundo. Pois é o modelo da linguagem e sua formação de realização - ou seja, o diálogo - que suporta não somente o entendimento entre os homens, senão também o entendimento das coisas que é feito o nosso mundo. ${ }^{10}$

Partindo desses pressupostos hermenêuticos podemos começar a delinear a idéia do círculo hermenêutico e sua importância para a interpretação. De acordo com Heidegger, explicado por Gadamer 11 , o círculo hermenêutico "descreve a forma de realização da própria interpretação compreensiva". Nessa visão a interpretação nunca começa de uma estaca zero, sempre começa dos preconceitos do intérprete, que os utiliza para compreender o texto que está interpretando, formado por signos significativos chamados de linguagem, sempre procurando entender seu todo a partir de suas partes e as partes a partir do todo.

Aqui é empregada uma visão sistemática da interpretação, na qual o objeto de estudo sempre tem que ser investigado de forma holística, a partir do sistema em que está localizado. Só se compreende a parte pelo todo, e o todo pela parte. Assim as palavras só tem significado em um contexto, na integração das partes com o todo, e o todo só é possível pelas partes que o compõe.

Por outro lado, a nossa pré-compreensão, ponto de partida da interpretação, é formada por toda a história de nossa vida em nível não consciente. É o início da formação ou deformação da compreensão. Formação, pois pode corroborar positivamente para a compreensão da linguagem, ou deformação, porque também pode trabalhá-lo de forma negativa, extraindo compreensão deformada do texto.

9 STRECK, Lênio Luiz. Hermenêutica Jurídica $\mathbf{e}(\mathrm{m})$ crise: uma exploração hermenêutica da construção do direito. Porto Alegre: Livraria do Advogado, 1999, p. 151-152.

10 STRECK, Lênio Luiz. Hermenêutica Jurídica $\mathrm{e}(\mathrm{m})$ crise: uma exploração hermenêutica da construção do direito. Porto Alegre: Livraria do Advogado, 1999, p. 169.

11 GADAMER, Hans-Georg. Verdade e método: traços de uma hermenêutica filosófica, $3^{\mathrm{a}}$ ed. Petrópolis: Vozes, 1999, p. 401 
Aproximamo-nos de um conjunto de símbolos linguísticos com a expectativa do sentido, quando o texto começa a falar podemos mudar nossa pré-compreensão, pois essa não é estabilizada, participando de uma constante mutação de valores. A compreensão de hoje é a pré-compreensão de amanhã.

A única forma de entendermos um texto é nos abrirmos para ele, considerando a nossa pré-compreensão apenas como rascunho, uma primeira impressão, fluída e efêmera que deve ser substituída pelo reconhecimento crítico do texto trabalhado a partir de leituras. De acordo com Gadamer:

\begin{abstract}
Quem quer compreender um texto, em princípio, disposto a deixar que ele diga alguma coisa por si. Por isso uma consciência formada hermeneuticamente tem que se mostrar receptiva, desde o princípio para a alteridade do texto. Mas essa receptividade não pressupõe uma "neutralidade" com relação a coisa nem tampouco auto-anulamento, mas inclui a apropriação das próprias opiniões prévias e preconceitos (...). O que importa é dar-se conta das próprias antecipações, para que o próprio texto possa se apresentar em sua alteridade e obtenha assim a possibilidade de confrontar sua verdade com as próprias opiniões prévias. $^{12}$
\end{abstract}

Mesmo construindo uma técnica interpretativa, o resultado interpretativo de cada um será diferente, tendo em vista que cada pessoa passa por diferentes realidades e experiências em sua vida, e que fazemos a interpretação baseada em nossos pré-juízos. Assim chegamos a problemática da interpretação verdadeira.

Se cada pessoa pode chegar a uma interpretação subjetiva diferente, ou pelo menos um conjunto delas possa chegar a algumas interpretações diferenciadas, então não há uma interpretação verdadeira, não existe um sentido unívoco para um texto ou uma música, por exemplo. Isto porque, a compreensão desses tipos de forma depende da pré-compreensão de cada um, de cada intérprete que se propõe a conhecer determinado objeto cognoscente.

Tomando como partida a parcialidade subjetiva do conhecimento, tentar agregar a alteridade da forma de entender o mundo fenomênico, possibilita que a integração de visões da realidade produza um resultado bem próximo dela. Devemos, assim, adotar o pluralismo das perspectivas e a integração dos pontos de vista a fim de se descobrir o todo. Desta forma, talvez nos aproximemos da própria realidade. Desconfiando de nossas certezas e integrando nossos pontos de vista para tentarmos alcançar o mínimo de objetivismo.

Não que se tome o objetivismo como sinônimo de realidade, nesta profusão de signos mundanos, mas o estabelecendo como marco de sustentação da realidade

12 GADAMER, Hans-Georg. Verdade e método: traços de uma hermenêutica filosófica, $3^{\mathrm{a}}$ ed. Petrópolis: Vozes, 1999, p. 405. 
(de alguma realidade). O ponto onde chegaremos nesta linha é um objetivismo intersubjetivista, ou seja, a integração dos pontos de vista, diversas opiniões subjetivas conciliadas que juntas são aceitas por uma coletividade, sendo esse o referencial de verdade dentro de uma comunidade, uma sociedade de homens.

Tendo como guia todos esses fatores trazidos pela hermenêutica filosófica de Heidegger e Gadamer na interpretação da linguagem devemos então defender o seu uso também para a ciência jurídica, pois como afirma Larenz: "É de expressões linguísticas que se trata, tanto nas leis como nas decisões dos tribunais e nos atos actos administrativos, e, em regra, também nos contratos". ${ }^{13}$

Apesar de Karl Larenz acreditar que existem expressões lingüísticas que não precisam de interpretação para compreensão, pois ela ocorre mediante processo irreflexivo de acesso imediato ao sentido da expressão, diferente de Gadamer, para quem compreender é sempre interpretar, o autor trás à colação, teses interessantes sobre a interpretação jurídica.

Para Larenz a interpretação de um texto normativo consiste na busca por um significado correto para os signos linguísticos que o compõem, em suas palavras:

\begin{abstract}
O intérprete tem presente os diferentes significados possíveis de um termo ou de uma sequência de palavras e pergunta-se sobre qual é aqui o significado correto. (...). A conclusão a que chega não é uma conclusão logicamente vinculante, mas uma opção, devidamente fundamentada, entre as diferentes possibilidades de interpretação. Interpretar um texto quer dizer, portanto, decidir-se por uma entre muitas possíveis interpretações, como em considerações que fazem aparecer tal interpretação como correta. ${ }^{14}$
\end{abstract}

Dessa forma vemos que os textos normativos, assim como qualquer outra emanação linguística, são formados por signos que requerem a interpretação para a sua devida compreensão. A interpretação, por sua vez, depende da pré-compreensão do intérprete, fazendo com que assim possamos achar diferentes interpretações para o mesmo signo linguístico dependendo de quem o está interpretando.

Esses fatores fazem, por conclusão, com que o direito seja um sistema aberto de significado, hermeneuticamente livre, uma vez que não há um significado verdadeiro, e sim diversos significados que podem ser extraídos dos signos lingǘsticos formadores dos textos normativos jurídicos.

13 LARENZ, Karl. Metodologia da ciência do direito, $3^{\text {a }}$ ed. Lisboa: Fundação Calouste Gulbenkian, 1997, p. 282.

14 LARENZ, Karl. Metodologia da ciência do direito, 3ª ed. Lisboa: Fundação Calouste Gulbenkian, 1997, p. 283 
Partindo destes pressupostos hermenêuticos, podemos demonstrar uma visão do direito a partir de sua interpretação e aplicação. Não interpretamos o direito somente quando a linguagem jurídica trás dificuldades para o entendimento, interpretamos o direito em todas as situações, em todos os casos.

O direito deve ser interpretado pois deve ser aplicado. Interpretação e aplicação não são duas operações diferentes, são dois momentos de uma mesma operação. Sempre que ocorrer uma situação, na qual a norma jurídica precisa ser aplicada então ocorre interpretação.

A interpretação ocorre porque são necessários fatos para desvelar a norma jurídica. Essa, por sua vez, não se confunde com os textos normativos. As normas são o resultado da interpretação dos textos normativos. "A interpretação é, portanto, atividade que se presta em transformar textos - disposições, preceitos, enunciados - em normas". ${ }^{15}$

Assim, o ordenamento jurídico é formado por um conjunto de textos normativos que são normas em potência, esperando ser desveladas pela interpretação a luz do caso concreto. Entretanto, uma norma não teria sentido se interpretada isoladamente. Além do texto normativo ser interpretado a luz dos fatos, também deve ser interpretado dentro do sistema em que está inscrito.

Exemplificando com a interpretação e aplicação de um princípio constitucional. Deveríamos começar do caso concreto - porque do nada, não pode surgir algo caminhar pela textualidade dos signos legais para adequá-los aos fatos chegando à contextualidade do sistema constitucional para dar sentido e consistência. Tudo para garantir que a solução na aplicação da norma jurídica corrobore com a logicidade sistêmica da unidade constitucional.

Dessa forma ocorre o círculo hermenêutico na interpretação/aplicação do direito, que começa em nossa pré-compreensão do texto legal e da situação, passa pela compreensão do texto a luz dos fatos e do sistema em que se insere, e finalmente desvelando a norma e partindo para sua aplicação. A interpretação do direito, por fim, consiste em sua aplicação. Não ocorre uma sem a outra.

Interpretar é aplicar. Não há separação entre compreensão, interpretação e aplicação; são todos momentos que se fundem sob a idéia geral de unidade de compreensão.

Nesse contexto, o intérprete produz a norma. Arranca-lhe do invólucro que a contém (texto legal) e a aplica ao caso concreto. Concretiza o direito em cada caso.

15 GRAU, Eros. Ensaio e Discurso sobre a interpretação/aplicação do direito, $4^{a}$ ed. São Paulo: Malheiros, 2006, p. 27. 
Não obstante, chegamos ao mesmo problema que dantes; aquele da interpretação verdadeira.

O texto é aberto e polissêmico, logo o sistema, também, é aberto de significado. Não tem significado verdadeiro, toda a linguagem normativa é de textura aberta, predisposta a múltiplas leituras e interpretações. O intérprete deve trabalhar no sistema formado por regras e princípios de forma a encontrar o melhor significado linguisticamente possível para aquele texto que esconde a norma.

Sendo assim, em um sistema aberto, de que forma poderemos ter certeza de qual o melhor significado a ser dado ao texto legal? De que maneira saberemos qual o mais democrático significado a ser dado ao direito? Será que existe interpretação verdadeira, e que caiba a nós, como intérpretes, achá-la nessa imensidão de resultados possíveis? Ou, então, a interpretação verdadeira não existe, e são necessários outros meios para legitimar a interpretação escolhida?

De maneira sintética, Ronald Dworkin crê na possibilidade de uma resposta verdadeira e Aulis Aarnio não. Nele outros mecanismos são necessários para legitimar a interpretação mais adequada. Vejamos as propostas de solução às questões postas.

\section{Democracia e legitimidade: a busca cooperativa.}

Atualmente duas grandes correntes costumam se opor no que tange a interpretação do direito: um grupo acredita que há uma resposta correta para os problemas jurídicos, enquanto outro acredita que devido à quantidade de resultados que podem ser bem fundamentados uma resposta correta é impossível, restando tão-somente a resposta mais bem fundamentada.

Esse é um embate possível nos dias de hoje devido a aproximação da teoria do direito com a hermenêutica filosófica de Heidegger e Gadamer, que demonstrou ser o sistema jurídico um sistema aberto de significado por ser formado por signos linguísticos livres de interpretação.

Passamos agora a investigar cada uma das doutrinas, com o objetivo de eleger a mais democraticamente apropriada para os nossos dias.

A doutrina da resposta correta não está cerrada em um único viés, não é uma doutrina homogênea, tem diversos planos que podem assim ser resumidos:

a) existe uma resposta correta que sempre será encontrada, e o intérprete saberá que a encontrou; b) sempre existe uma resposta correta que 
pode ser encontrada, embora, na prática, nem sempre se tenha êxito (...) c) a resposta correta é um ideal que nunca pode ser alcançado, mas que constitui o propósito regulativo de toda a interpretação jurídica. ${ }^{16}$

Além desses planos existentes ainda existe outro no qual se situa a teoria da resposta correta de Dworkin, segundo Aarnio:

É verdade que Dworkin não argumenta que em cada caso existe uma resposta correta, mas acredita que, em princípio, ela é possível e, na maioria dos casos, existe tal solução. Dworkin admite que ocorram situações (juízos de empate) onde podem ser justificados tanto os direitos do demandante quanto os direitos do demandado. Em tal situação é impossível dizer qual é a resposta correta. Mas também há casos em que a idéia da resposta correta pode ser claramente defendida. ${ }^{17}$

Mesmo não defendendo a existência constante de uma resposta correta para o direito, Dworkin defende que em diversos casos ela pode ser encontrada, principalmente por meio da interpretação do problema e dos direitos dos indivíduos, que independem de qualquer decisão de autoridades de determinado Estado.

Para Dworkin ${ }^{18}$ o direito existe independente das decisões de autoridade, ou seja, as decisões corretas às vezes não estão adormecidas na letra da lei, mas em outras diferentes fontes do direito. Nesse contexto Dworkin define o direito como integridade. Ele constata que o direito mantém vínculos fortes com a moral e a política, pressupondo uma indiferenciação quase total entre direito e moral.

Nesse diapasão, Dworkin acredita que ao juiz "cabe sempre descobrir a resposta correta, que está oculta no direito pré-existente". ${ }^{19}$ É a figura do juiz Hércules, o juiz-filósofo perfeito, aquela figura em que todos os juízes deveriam se mirar, pois sempre leva em consideração todos os fatos, direitos e casos para sua interpretação, agindo de forma a encontrar a resposta correta e a melhor justificação para ela.

Deste modo, a teoria de Dworkin trabalha com a verdade, ou seja, o doutrinador acredita que em certos casos, cumprindo o juiz seu papel dado pelo Estado, poderia se chegar, por meio da interpretação, à verdade, a uma resposta verdadeira. Essa questão nos trás uma visão objetiva da moral social, pois a resposta verdadeira encontrada por Hércules não se dá porque ele crê que seja verdade, ou

16 DOBROWOLSKI, Samantha Chantal. A justificação do direito e sua adequação social: uma abordagem a partir da teoria de Aulis Aarnio. Porto Alegre: Livraria do Advogado, 2002. p. 90.

17 AARNIO, Aulis. Lo racional como razonable: un tratado sobre la justificación jurídica. Madrid: Centro de Estudios Constitucionales, 1991, p. 214.

18 DWORKIN, Ronald. Uma questão de princípio. São Paulo: Martins Fontes, 2001, p. 251-266.

19 DOBROWOLSKI, Samantha Chantal. A justificação do direito e sua adequação social: uma abordagem a partir da teoria de Aulis Aarnio. Porto Alegre: Livraria do Advogado, 2002, p. 111. 
porque há um consenso social que acredita ser a resposta uma verdade, mas porque é baseada na moral coletiva objetiva, onde algo apenas "é" verdade, sem demais justificações.

Vimos que não é possível encontrar a verdade dessa forma, pois cada pessoa tem sua interpretação da realidade baseada em seus preconceitos, e a proximidade máxima que podemos chegar da verdade é o consenso social por meio do diálogo, uma busca cooperativa pela verdade. Do modo que Dworkin propõe a "verdade" apenas é lançada por alguém (Hércules) que crê que pode achá-la na maioria dos casos, e não uma crença democrática no diálogo e no compartilhamento de opiniões e pontos de vista. Deste modo, é pouco crível que alguém - entenda-se alguém fora do campo de possibilidades do Olimpo - possa chegar a esta verdade. Qual seria a diferença entre a verdade dessa pessoa e de outro intérprete?

Isto nos leva à tese sobre interpretação jurídica e aceitabilidade racional de Aulis Aarnio. O autor não ratifica a tese de Dworkin a respeito dos valores absolutos, acredita sim na possibilidade de "várias interpretações igualmente bem fundamentadas", pois "não há resposta correta na interpretação jurídica (tese ontológica) e tampouco respostas deste tipo podem ser descobertas pelo intérprete (tese epistemológica e metodológica)".20

Por meio de sua tese da aceitabilidade racional Aarnio busca refutar a crítica de que uma teoria que aceite diversas interpretações ou respostas para um caso vai de encontro à própria essência do direito, pois destrói qualquer possibilidade de segurança jurídica deixando o direito ao arbítrio daqueles que decidem.

Nas palavras do autor a aceitabilidade racional pode ser conceituada como:

A aceitabilidade racional é uma propriedade do resultado final do procedimento de justificação jurídica. Portanto, fala-se da aceitabilidade racional de pontos de vista interpretativos. Por sua vez, no que diz respeito à sua natureza, a interpretação jurídica é um diálogo, ou seja, nesse sentido, uma forma de comunicação humana. Assim, seguindo Jürgen Habermas, pode-se chamar este tipo de racionalidade, de racionalidade comunicativa. Ela está vinculada à argumentação e ao convencimento. Por conseguinte, a razão comunicativa é a base da compreensão humana e, também, a base da aceitabilidade. ${ }^{21}$

Como dito pelo autor a base da aceitabilidade racional está no diálogo. No poder encontrado nas palavras para, por meio do diálogo, fazer as partes dialogantes

20 DOBROWOLSKI, Samantha Chantal. A justificação do direito e sua adequação social: uma abordagem a partir da teoria de Aulis Aarnio. Porto Alegre: Livraria do Advogado, 2002, p. 92.

21 AARNIO, Aulis. Lo racional como razonable: un tratado sobre la justificación jurídica. Madrid: Centro de Estudios Constitucionales, 1991, p. 241. 
chegarem a um consenso, a um tipo de compreensão recíproca que satisfaça ambos os lados.

A comunicação, por sua vez, é fundada no poder do livre argumento, o melhor argumento é aquele que é aceito e tomado como correto para determinada situação pela platéia de intérpretes ${ }^{22}$, pela comunidade dos investigadores. Logo, para se chegar a melhor decisão é necessário abrir os locais de diálogo, abrir os locais de decisão, dando voz a outros intérpretes e agentes sociais que buscam por uma forma mais plural de se enxergar o direito e a sociedade.

Sempre haverá divergências de opinião, pois cada intérprete tem seu próprio conhecimento de mundo, porém por meio do diálogo essas divergências podem ser atenuadas ou até ultrapassadas. ${ }^{23} \mathrm{~A}$ comunicação e discussão são essenciais para a aceitabilidade racional das decisões em um Estado Democrático.

Toda a argumentação visa influenciar um auditório, toda a argumentação tem como fim obter adesão daqueles a quem se dirige. A argumentação jurídica não é diferente. Das diversas interpretações que podemos fazer de um caso, a argumentação serve para convencer aqueles que devem ser convencidos, ou seja, o auditório que espera a decisão.

A partir do momento que a audiência partilha mesmos valores e aceita seguir as regras racionais do discurso, o diálogo e o debate trazem a maximização da certeza jurídica, pois, por meio dele, os interessados podem trazer suas interpretações e utilizar de sua própria argumentação para tentar convencer os outros de seu ponto de vista, assim como pode ocorrer o contrário, e esse agente acabar convencido pelo ponto de vista de outra pessoa. ${ }^{24}$

22 Neste ponto, o discurso se assemelha à Chaim Perelman quando a unificação de opiniões fornece o princípio necessário para a fundamentação da ação moral, retirando-lhe o caráter de arbitrariedade. Segundo ele, “o uso da argumentação implica que se tenha renunciado a recorrer unicamente à força, que se dê apreço à adesão dos interlocutores, obtida graças a uma persuasão racional, que esse não seja tratada como um objeto, mas que se apele à sua liberdade de juízo. O recurso à argumentação supõe o estabelecimento de uma comunidade dos espíritos que, no entanto dura, exclui o uso da violência”. Chaim Perelman e Lucie Olbrechts-Tyteca. Tratado da Argumentação: a nova retórica. São Paulo: Martins Fontes, 2002, p. 61.

23 O pressuposto ontológico da inexistência de uma resposta una, longe de fulminar a proposta, incentiva a produção do objetivismo intersubjetivista que passa a gozar de legitimidade suficiente para ser tratada como se verdade o fosse.

24 Lógico que a tese pressupõe a mesma oportunidade argumentativa dos agentes, o que não deixa de ser um fundamento preocupante se observarmos a realidade social das diversas comunidades estatais. 
Uma audiência ideal e particular é um grupo em que um consenso racional pode ser alcançado. Isto é muito importante do ponto de vista da relevância social das interpretações da dogmática jurídica. (...) Isto significa, especificamente, que as partes do diálogo tenham alcançado, numa base racional, um consenso sobre o assunto. De acordo com isso, um ponto de vista interpretativo apoiada por um maior consenso racional tem uma maior relevância social. (...) A dogmática jurídica deve ter a intenção de buscar aquelas interpretações jurídicas que podem contar com o apoio da maioria em uma comunidade jurídica que argumenta de forma racional. ${ }^{25}$

Assim, de acordo com Aarnio, como muitas interpretações são juridicamente possíveis dentro do sistema aberto de significado que é o direito, então o papel da dogmática jurídica consiste em encontrar a interpretação mais aceita pela comunidade que pensa racionalmente, buscando, dessa forma, legitimidade para as decisões tomadas.

Essa é a principal diferença entre a tese de Dworkin e a tese de Aarnio. Enquanto Dworkin busca pela verdade por meio de seu procedimento, Aarnio busca pela legitimidade da decisão mais aceita pela sociedade. Esse é o embate: verdade versus legitimidade!

A legitimidade das decisões gerada pelo o consenso é o mais próximo que

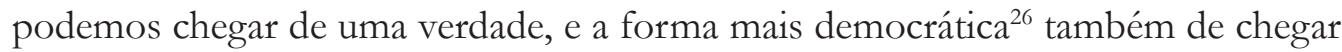
a esse destino. E o único caminho para isso é por meio da busca cooperativa da sociedade racional, que pensa e espera o melhor para todos os seus membros.

Esse ponto de vista pode ser criticado de diversas formas, mas a crítica mais contundente que pode ser arguida é a distância da realidade. Posto que, conceitos como aceitabilidade racional e consenso legítimo são modelos ideais e pouco provavelmente fáticos.

Temos outra visão sobre o assunto. Certo que os conceitos aqui debatidos são conceitos ideais, que ainda não se encontram de todo no mundo real. Porém, partimos do preconceito, à la Gadamer, democrático o que garante a Aarnio um passo adiante na solução do problema.

É necessário que as pessoas que são alvo das decisões as aceitem de forma entendida e racional, pois só assim caminharemos no rumo da legitimidade e democracia, no rumo onde a verdade não é verdade por si só, mas porque partiu do consenso daqueles que partilham determinada vivência.

25 AARNIO, Aulis. Lo racional como razonable: un tratado sobre la justificación jurídica. Madrid: Centro de Estudios Constitucionales, 1991, p. 285-286.

26 Não parece, no entanto, que Aarnio se ponha a questão da legitimação da maioria pelo todo que tem sido um campo de longos debates nos estudos que se fazem da Teoria da Democracia. 


\section{Considerações Finais.}

À guisa de fechamento, tentamos desmistificar a interpretação e a aplicação do direito, utilizando-nos de argumentos que demonstrassem que a operação interpretativa vai muito além da mera subsunção da norma ao caso concreto.

Mostramos que a interpretação é essencial para o ser humano, pois toda a linguagem deve ser interpretada para ser compreendida, e a linguagem é a forma última de inclusão e compreensão do mundo que nos cerca.

O próprio direito posto é formado por signos linguísticos, logo a interpretação é essencial para sua compreensão e aplicação. A norma jurídica nasce dessa operação de interpretação, pois está enclausurada nos textos legais que fazem parte do ordenamento jurídico.

Toda a interpretação depende de um intérprete, e a interpretação de cada intérprete depende dos seus preconceitos sobre o assunto, de suas pré-compreensões. Dessa forma podem ser dadas diversas interpretações para o mesmo texto, inclusive os textos jurídicos, fazendo com que o direito seja um sistema aberto e livre de significado.

O que nos leva ao problema da interpretação jurídica correta, de que forma podemos encontrar uma interpretação verdadeira para o direito. A resposta proposta é que não se pode encontrar a verdade, pois ela não existe. O que existe é um consenso social racional sobre as interpretações, ou seja, o mais próximo que podemos chegar da verdade é a crença de muitas pessoas em determinada interpretação. Portanto, a única verdade é a intersubjetiva, baseada no consenso social.

Só podemos chegar ao consenso por meio de uma busca cooperativa, através do diálogo. A única decisão realmente democrática é aquela que é aceita pelas pessoas que suportarão seus ônus, e que puderam dialogar para nela chegar.

Realmente a tese de Aarnio aqui demonstrada tem mais apelo democrático e social que a de Dworkin. Se dermos chances a todos para discutir sobre os problemas enfrentados teremos realmente decisões mais democráticas ${ }^{27}$, por atenderem a opinião de diversos locutores.

27 Recordando-se aqui novamente da opção político-metodológica pela Democracia. 
O que fica ainda sem resposta nessa perspectiva é de que forma se chegaria nesse consenso? Teriam os locutores base teórica e conhecimento para discutir os problemas que se apresentam? Como deixaríamos de lado o egoísmo humano para gerar decisões que a todos fizessem bem, e não só a uma parcela da sociedade?

Para nós são perguntas que esgotam a capacidade de resposta da tese exposta. Idealmente, no entanto, a proposição de decisões mais racionais baseadas no consenso é mais atrativa, porém não a vemos de todo amparada na realidade. Seria a teoria perfeita para um mundo ideal, porém este não é o nosso mundo.

A tese de Aarnio é atraente e auxilia na compreensão do fenômeno interpretativo sob um prisma democrático. $\mathrm{E}$ neste sentido ela proporciona um avanço teorético-sistêmico, mesmo assim não podemos confundíla com a realidade. Ela não representa a realidade e nem a realidade é representada por ela. É puramente um modelo ideal.

Dessa forma não podemos ainda utilizá-la de forma integral, por não ter todas as bases concretas de nossa realidade material. Talvez quando consigamos responder àquelas questões feitas acima a tese da correção das respostas judiciais baseadas no consenso da racionalidade razoável possa ser utilizada com maior envergadura. Por enquanto, contudo, ainda nos encontramos em busca destas respostas, destas conclusões. 


\section{Referências}

AARNIO, Aulis. Lo racional como razonable: un tratado sobre la justificación jurídica. Madrid: Centro de Estudios Constitucionales, 1991.

DOBROWOLSKI, Samantha Chantal. A justificação do direito e sua adequação social: uma abordagem a partir da teoria de Aulis Aarnio. Porto Alegre: Livraria do Advogado, 2002.

DWORKIN, Ronald. Uma questão de princípio. São Paulo: Martins Fontes, 2001.

GADAMER, Hans-Georg. Verdade e método: traços de uma hermenêutica filosófica, $3^{\mathrm{a}}$ ed. Petrópolis: Vozes, 1999.

GRAU, Eros. Ensaio e Discurso sobre a interpretação/aplicação do direito, $4^{\mathrm{a}}$ ed. São Paulo: Malheiros, 2006.

LARENZ, Karl. Metodologia da ciência do direito, $3^{a}$ ed. Lisboa: Fundação Calouste Gulbenkian, 1997.

NUNES, Benedito. Heidegger \& Ser e Tempo. Rio de Janeiro: Jorge Zahar, 2002.

PALMER, Richard E. Hermenêutica. Lisboa: Edições 70, 1969.

STRECK, Lênio Luiz. Hermenêutica Jurídica e $(m)$ crise: uma exploração hermenêutica da construção do direito. Porto Alegre: Livraria do Advogado, 1999. 